\title{
Moving ahead or falling behind?
}

\author{
Stephen B Hanauer
}

Constipation is such a simple problem-wrong! For a symptom that is so commonplace in a gastroenterologist's practice, and a pathophysiological process that is so well understood, the development of pharmaceutical therapies should be straightforward and financially rewarding. Amazingly, however, the number of pharmacological formulations that have been approved by the FDA for the treatment of constipation is falling rather than rising.

If we expand the context to consider IBS in general, the picture is even grimmer. Cisapride, initially thought to be a relatively benign drug, was originally approved in the US for the treatment of nocturnal heartburn. Despite being prescribed to millions of patients worldwide, cisapride was withdrawn from the market because cardiac arrhythmias occurred in a small number of patients (often related to drug-drug interactions or a prolonged QT interval). The use of cisapride is now severely restricted and most gastroenterologists will, presumably, miss having the option to prescribe this drug for patients with gastroparesis or other motility disorders.

Although the benefit-to-risk ratio for nocturnal heartburn was not met, the frequent off-label use of cisapride as a prokinetic had not been demonstrated to be safe and effective at the level required for regulatory acceptance. Having sat on (and chaired) the FDA advisory panel, however, I recognize the difficulties associated with studying prokinetics in clinical trials. The failure to launch domperidone in the US is another example of the difficulties associated with the design and interpretation of clinical trials of gastrointestinal motility agents.

Most recently, tegaserod, a serotonin 5-hydroxytryptamine 4 antagonist receptor, has been voluntarily withdrawn from the market because of an increased cardiovascular risk identified in a pooled analysis of short-term, randomized, controlled clinical trials involving more than 18,000 patients (Public Health Advisory 30 March 2007; http:// www.fda.gov/cder/drug/advisory/tegaserod.htm). The pooled analysis demonstrated a higher risk of ...from a

population

standpoint, and for the

millions of

people who

suffer from

motility

disorders, what the

world needs

now is a safe and effective prokinetic agent

SB Hanauer is Editorin-Chief of Nature Clinical Practice Gastroenterology \& Hepatology.

\section{Competing interests}

The author has served as a consultant to Novartis.

www.nature.com/clinicalpractice doi:10.1038/ncpgasthep0821 serious cardiovascular adverse events associated with use of tegaserod compared with placebo. Cardiovascular ischemic events were confirmed in 13 patients treated with tegaserod $(0.1 \%)$ and only 1 patient treated with placebo $(0.01 \%)$. On the basis of these data, the FDA concluded that the benefits of tegaserod no longer outweigh the risks. Again, I suspect that off-label use of tegaserod as a prokinetic for patients with treatmentrefractory motility disorders rather than benign constipation was substantial, especially in tertiary centers.

The horizon isn't that clear. The development of alvimopan, a peripherally acting mu opioid receptor antagonist that is an effective treatment for opioid-induced constipation, has also been interrupted by an increased risk of cardiovascular events. Results from the recent phase III trial in more than 800 patients taking opioids for chronic noncancer pain and experiencing opioid-induced bowel dysfunction demonstrated a statistically nonsignificant imbalance in the number of cardiovascular serious adverse events among patients treated with alvimopan (14 patients, 2.6\%) compared with placebo (3 patients, 1.12\%). The sponsor reports that "The [cardiovascular serious adverse events] reported ... occurred in patients with established or at high risk for [cardiovascular] disease." (News Release April 9 2007; http://phx.corporate-ir.net/ phoenix.zhtml?c=120919\&p=irol-newsArticle\&t= Regular\&id=982960). Could the explanation simply be that patients whose symptoms were improved by alvimopan were more mobile and, hence, more susceptible to cardiovascular events than placebo-treated patients?

Compared with treatments for neoplastic or chronic inflammatory disorders, treatments for functional gastrointestinal disorders require a higher level of scrutiny and benefit-to-risk ratio. The standard has not yet been set: from a population standpoint, and for the millions of people who suffer from motility disorders, what the world needs now is a safe and effective prokinetic agent. 